Review

\title{
Photocurable Polymers for Ion Selective Field Effect Transistors. 20 Years of Applications
}

\author{
Natalia Abramova* and Andrei Bratov \\ Instituto de Microelectrónica de Barcelona (IMB-CNM-CSIC), Campus UAB, 08193 Bellaterra, \\ Barcelona, Spain; E-Mail: andrei.bratov@imb-cnm.csic.es \\ * Author to whom correspondence should be addressed; E-Mail: natalia.abramova@imb-cnm.csic.es; \\ Tel.: +34-935-947-700; Fax: +34-935-801-496.
}

Received: 10 June 2009; in revised form: 27 August 2009 / Accepted: 29 August 2009 / Published: 7 September 2009

\begin{abstract}
Application of photocurable polymers for encapsulation of ion selective field effect transistors (ISFET) and for membrane formation in chemical sensitive field effect transistors (ChemFET) during the last 20 years is discussed. From a technological point of view these materials are quite interesting because they allow the use of standard photolithographic processes, which reduces significantly the time required for sensor encapsulation and membrane deposition and the amount of manual work required for this, all items of importance for sensor mass production. Problems associated with the application of this kind of polymers in sensors are analysed and estimation of future trends in this field of research are presented.
\end{abstract}

Keywords: ISFET; photocurable; polymers; membrane; chemical sensor

\section{Introduction}

The field of chemical sensors based on microelectronic devices has been the topic of considerable research in the last decades and has been largely focused on ion selective field effect transistors. This interest arises from certain advantages of ISFETs over conventional ion-selective electrodes (ISE) such as a small size and solid nature, short response times and low output impedance and the possibility of mass fabrication. Other features such as the integration of compensation and data processing circuits in the same chip also offered new perspectives for these sensors. 
The response mechanisms of ISFET-based sensors are based on the electrochemical phenomena occurring within the chemically sensitive membrane placed on top of the transistor gate [1] and on electrical transduction of the signal by this semiconductor device. To exploit the advantages offered by modern technologies in a fabrication of solid-state chemical sensors based on ISFETs new requirements are imposed on any potential matrix for ion sensor membranes, namely the adhesion of membranes to a solid substrate and the compatibility of any ion-sensitive membrane deposition process with microelectronic technology.

Finally, the main obstacle preventing widespread production of ISFETs and chemically sensitive field effect transistors (ChemFETs) is the lack of a good sensor chip encapsulation procedure. Though ISFETs are now commercially available, most encapsulation procedures used are done manually.

To resolve these problems the most feasible approach from technological point of view is to use polymer materials that may be cured by UV light. The use of photocured polymeric systems permits one to employ a standard photolithographic process, which reduces significantly the time of membrane deposition and facilitates the encapsulation process reducing the manual work required for it, items that are all important for sensor mass production.

\section{Encapsulation of ISFET Sensors}

Packaging of chemical microsensors based on ISFET devices produced by silicon planar technology is one of the most important and critical steps in their whole realisation process. For industrial applications a complete automatization of the fabrication process is necessary. Several techniques have been developed for this by applying microtechnologies such as photolithography [2], electrochemical deposition [3], anodic bonding [4] and micromachining [5].

The most promising from a technological point of view is the application of photosensitive encapsulants. Among the materials used are polyimide covered by a standard photoresist [6] and photocurable epoxy acrylate [7]. Polyimide is widely used in semiconductor and packaging technologies because of its high thermal stability and good insulation properties. The problem in applying photosensitive polyimides for encapsulation is that it is difficult to deposit and to selectively etch thick $(>20 \mu \mathrm{m})$ films of this material [8]. Moreover it is not chemically stable in highly basic solutions.

Multifunctional acrylates are widely used in different industries for production of UV cured coatings. These materials are usually characterised by their high reactivity and give insulating coatings with good weatherability and high resistance to solvents. Acrylates upon exposure to UV undergo polymerisation via radical or cationic mechanisms, depending on a photoinitiator used. Radical polymerisation, being a faster process, is preferred in most cases. The polymer layer after being applied to a wire bonded sensor glued to some substrate can be patterned using traditional photolithography techniques. The properties of the resulting encapsulant will depend on the chemical structure of the prepolymer used. In choosing a suitable prepolymer it must be taken into consideration that is has to satisfy certain requirements, namely:

- Good chemical resistance in highly acidic or alkaline media

- Low permeability for any kinds of chemical compounds

- Good adhesion to a solid substrate (silicon, silicon oxide or silicon nitride)

- Easy processing 
- High electrical resistance for preventing leakage current

- Mechanical strength and low shrinkage

- Biocompatibility in the case of biomedical applications

Investigations $[9,10]$ have shown that acrylate derivatives of aliphatic urethane and bisphenol A (epoxy) resins are promising materials for ISFET sensor encapsulation, which along with good insulating properties posses good chemical resistance. A multilayer deposition method was developed where to enhance the adhesion of a thick polymer film covering the mounted and wire bonded chip a first thin layer of photocurable encapsulant is initially deposited directly on a wafer (Figure1).

Figure 1. ISFETs wafer with the thin layer of photocurable encapsulant - 1, opening over the gate region -2 , contact pads -3 and scribing lines -4 .

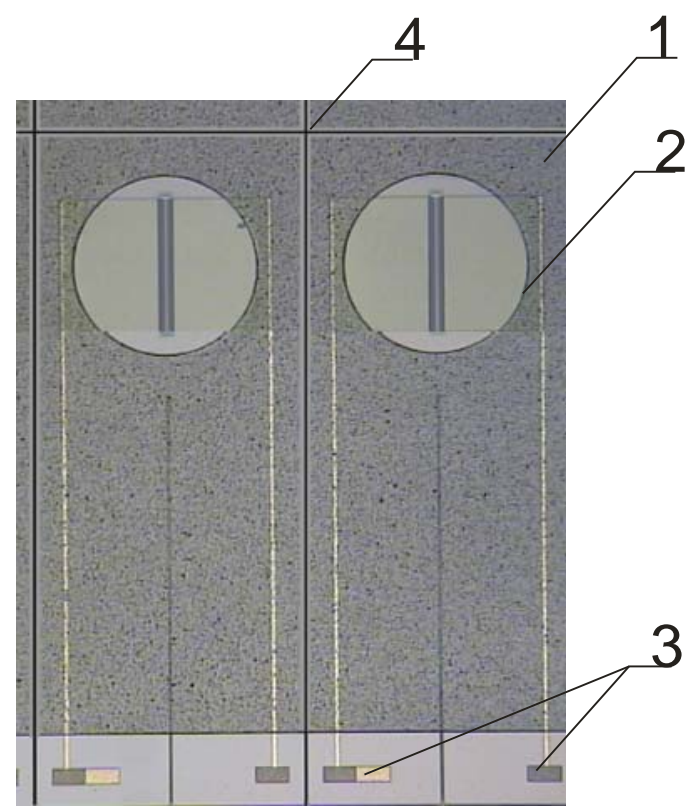

The layer (1) is patterned to open precisely the gate (2), contact pads (3) and scribing lines (4).

Figure 2. ISFET sensor mounting and encapsulation process (explanation in the text).

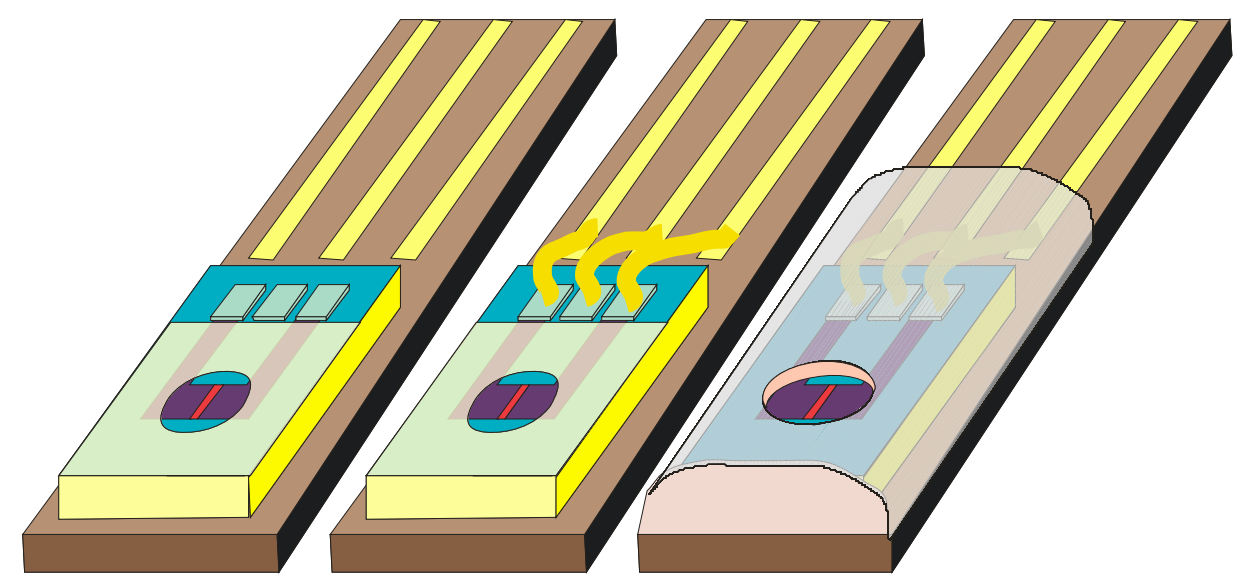


An ISFET sensor mounting and encapsulation process is presented schematically on Figure 2. After cutting the wafer the chips are glued to the PCB plate with contact lines (1) and are wire bonded (2) to provide a contact to source, drain and silicon substrate. The plates with wire bonded sensors are fixed in a mould where they are covered with a thick $(100-200 \mu \mathrm{m})$ layer of the encapsulant. After exposure to UV through a mask that protects the gate region, the polymer is developed leaving the opening in the encapsulant (3). Figure 3 presents the photograph of the ISFET chip encapsulated by this method. These types of sensors are provided by $\mathrm{D}+\mathrm{T}$ Microelectrónica (Spain) for special applications according to user requirements.

Figure 3. Photograph of a wire bonded and encapsulated ISFET chip.

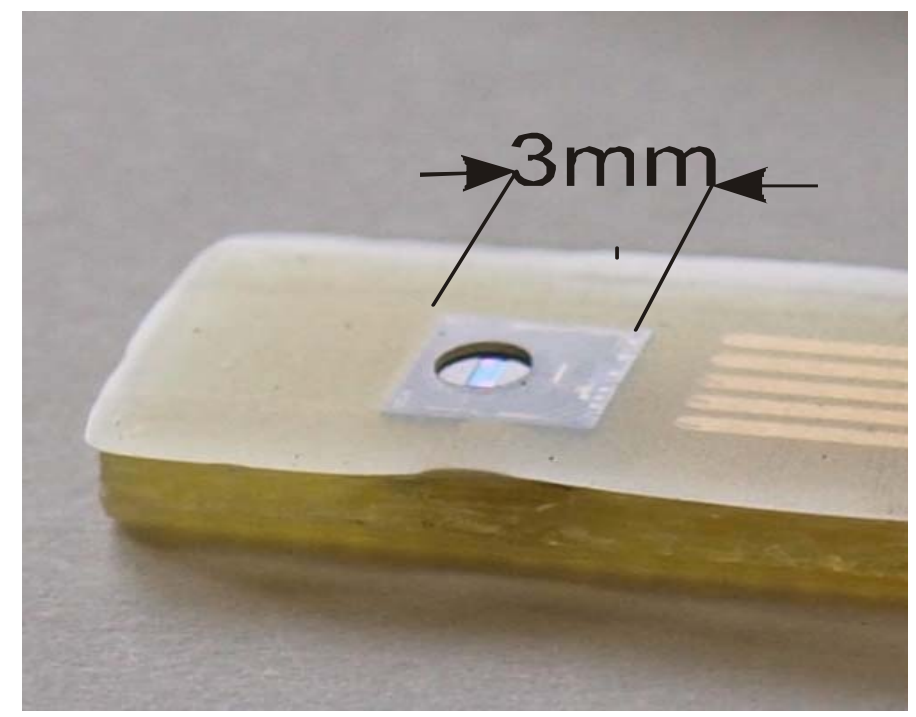

Table 1. Photocurable applied polymers as membrane matrices for chemical sensors.

\begin{tabular}{|c|c|c|c|}
\hline Type of polymer & Analyte & Type of sensor & Reference \\
\hline \multicolumn{4}{|l|}{ ACRYLATES } \\
\hline Bisphenol A epoxyacrylate (Ebecryl 150) & $\mathrm{Ca}^{2+}$ & SCE & [11] \\
\hline \multirow{4}{*}{ Bisphenol A epoxyacrylate (Ebecryl 600) } & $\mathrm{Ca}^{2+}$ & SCE, CWE & [12-13] \\
\hline & $\mathrm{K}^{+}$ & SCE & [14-15] \\
\hline & $\mathrm{Li}^{+}$ & SCE & {$[16]$} \\
\hline & $\begin{array}{c}\mathrm{NH}_{4}^{+}, \mathrm{Ca}^{2+}, \mathrm{pH} \\
\mathrm{K}^{+}, \mathrm{Cl}^{-}, \mathrm{NO}_{3}^{-}\end{array}$ & CWE & [17] \\
\hline Epocryl DRH 370 & $\mathrm{~K}^{+}$ & ISFET & {$[18]$} \\
\hline \multirow{8}{*}{$\begin{array}{l}\text { Aliphatic urethane diacrylate } \\
\text { (Ebecryl 270) }\end{array}$} & $\mathrm{K}^{+}, \mathrm{NH}_{4}^{+}, \mathrm{Ca}^{2+}$ & ISFET & {$[19],[20],[21]$} \\
\hline & $\mathrm{Cl}^{-}, \mathrm{Na}^{+}$ & ISFET & {$[22],[23]$} \\
\hline & $\mathrm{CO}_{3}^{2-}$ & ISE & [24] \\
\hline & $\mathrm{pH}$ & SCE & [25] \\
\hline & monochloroacetate & SCE & {$[26]$} \\
\hline & urea & ISFET & [27] \\
\hline & glucose & Microelectrode & [28] \\
\hline & anionic surfactants & ISFET & [29] \\
\hline
\end{tabular}


Table 1. Cont.

\begin{tabular}{|c|c|c|c|}
\hline Polyacrylamide & Glucose, urea & ISFET & {$[30]$} \\
\hline Dodecyl acrylate & $\mathrm{Cl}^{-}, \mathrm{NO}_{3}^{-}, \mathrm{ClO}_{4}$ & Optical sensor & [31] \\
\hline Acrylic acid and acrylonitrile & Reference electrode & SCE & [32] \\
\hline Isodecylacrylate and acrylonitrile & $\mathrm{Na}$ & SCE & {$[33]$} \\
\hline \multicolumn{4}{|l|}{ METHACRYLATES } \\
\hline Butyl methacrylate & $\mathrm{Ca}^{2+}$ & ISFET & {$[2]$} \\
\hline $\begin{array}{l}\text { Bisphenol A-bis(2-hydroxypropyl- } \\
\text { methacrylate) }\end{array}$ & $\mathrm{NO}_{3}^{-}$ & SCE, ISFET & [34-35] \\
\hline \multirow{2}{*}{ Polysiloxanes } & $\mathrm{Ca}^{2+}$ & ISFET & {$[36]$} \\
\hline & $\mathrm{K}^{+}, \mathrm{NO}_{3}^{-}$ & ISFET & [37-39] \\
\hline $\begin{array}{l}\text { Butyl-, nonyl-, 1,4-butanduol-, 1,6-hexandiol } \\
\text { methacrylates }\end{array}$ & $\mathrm{Ca}^{2+}$ & ISFET & {$[40]$} \\
\hline \multirow{2}{*}{$\begin{array}{l}\text { Bisphenol A-diglicidyletherdi- } \\
\text { methacrylate }\end{array}$} & $\begin{array}{l}\mathrm{NO}_{3}^{-}, \mathrm{BF}_{4} \text {, dicyanoureate, } \\
\text { dicyanoargentate }\end{array}$ & $\mathrm{SCE}$ & {$[41]$} \\
\hline & $\mathrm{K}^{+}, \mathrm{Ca}^{2+}$ & ISFET & {$[42]$} \\
\hline Metyl-, $n$-butyl methacrylates & $\mathrm{K}^{+}, \mathrm{Na}^{+}, \mathrm{pH}, \mathrm{Ca}^{2+}$ & SCE & {$[43,44]$} \\
\hline Methyl-, decyl methacrylate & $\mathrm{K}^{+}$ & Optical sensor & {$[45]$} \\
\hline Oligosiloxane methacrylate & $\mathrm{K}^{+}, \mathrm{Ca}^{2+}$ & ISFET, SCE & {$[46]$} \\
\hline Methyl-, butyl-, glycidyl methacrylates & $\mathrm{K}^{+}, \mathrm{Ca}^{2+}, \mathrm{Cs}^{+}, \mathrm{Li}, \mathrm{Mg}^{2+}$ & LAPS & {$[47]$} \\
\hline $\begin{array}{l}\text { Hydroxyethyl methacrylate-co-methacrylic } \\
\text { acid }\end{array}$ & $\mathrm{pH}$ & $\begin{array}{l}\text { Holographic } \mathrm{pH} \\
\text { sensor }\end{array}$ & {$[48]$} \\
\hline Polymethacrylate & glucose & SCE & [49] \\
\hline Glycidyl methacrylate & $\begin{array}{l}\text { Urea, acetylcholine, } \\
\text { butyrylcholine, } \mathrm{Cd}^{2+}\end{array}$ & LAPS & {$[50]$} \\
\hline \multicolumn{4}{|l|}{ OTHERS } \\
\hline Styrene-vinylbenzol & $\mathrm{K}^{+}$ & ISFET & {$[51]$} \\
\hline Poly(vinyl alcohol) & Glucose, urea & ISFET & {$[52]$} \\
\hline \multirow{2}{*}{ PVA-SbQ* } & Glucose, sucrose & ISFET & {$[53]$} \\
\hline & Urea, trichlorfon, & ISFET & {$[54-56]$} \\
\hline
\end{tabular}

ISE - conventional ion selective electrode, SCE - solid contact electrodes, CWE - coated wire electrode, LAPS

- light addressable potentiometric sensor,

* PVA-SbQ - polyvinyl alcohol functionalised with methyl pyridinium methyl silphate

\section{Membrane Formation}

The best known method of ISFET membrane formation comes from traditional ion selective electrodes and is based on using a polymer matrix which is deposited over an ISFET gate and contains the required ion active components, like ionophore, plasticizer and lipophilic additives. Achievements in development of traditional ISE with liquid inner contact resulted in hundreds of different membrane compositions that can be used as well in case of ISFETs 
The most common polymer matrix for membrane ISEs is polyvinyl chloride (PVC). Unfortunately, its use in ISFET-based sensors is limited due to poor adhesion of PVC to a solid support which leads to peeling of membranes, producing drift in sensor parameters and short sensor operational lifetimes. Another drawback is the manual deposition of membranes by solvent casting which requires long curing times under ambient conditions with controlled partial pressure of the solvent. And the last problem that face PVC-based membrane ISFETs is the leaching of membrane components from rather thin $(30-100 \mu \mathrm{m})$ membranes, resulting in changes in the membrane composition and deterioration of sensor parameters.

Photocurable polymers as an alternative material for membrane matrices for ISFETs, solid contact electrode (SCE) and coated wire electrode (CWE) were introduced by different research groups in the middle of 1980s, and early 1990s. Bibliographic data on application of photocurable polymers for chemical and ion sensor development are summarized in Table 1. Among the different photocurable polymeric systems acrylates and methacrylates are the most commonly used. Coated wire electrodes selective to calcium and potassium ions with membranes based on commercial epoxyacrylates were studied by an Australian group [11,13-15]. Later the same polymer was used for the development of a Ca-selective electrode [12] and for a nitrate sensitive ISFET [34,35], but with different polymerisation schemes. This polymer was also applied to fabricate a six sensor array of coated-wire electrodes for use in a portable flow-injection analyzer [17].

In 1994 Bratov et al. [57] demonstrated that polyurethane based photocurable polymers may be regarded as an appropriate matrix for ISFETs ion selective membranes. This polymer matrix contains a small amount of anionic impurities that cause intrinsic cationic permselectivity [19]. Being compatible with various plasticizers traditionally used in ion selective membrane formulations, it may be used to make different sensors selective to cations [19-21] as well as anions [22-24]. For proper functioning the membrane with cation selective neutral carrier as an ionophore should contain at least $35 \%$ of a suitable plasticizer and small amounts of a salt with a highly lipophilic anion (K-TpClPB). Polyurethane polymers showed excellent adhesion to silylated silicon oxide surface giving membranes with a long (more than 6 months) life-time during constant contact with solutions.

Polysiloxane was used not only as a supporting material for ISFETs but as a polymer that allowed research groups from the University of Neuchatel [36-39] and the University of Twente [38] to covalently attach an ionophore and anionic sites to the membrane matrix. Among other photocurable materials styrene-vinylbenzol copolymer [51] and different types of poly(vinyl alcohol) (PVA) [52-56] were reported. PVA as well as polyacrylamide [30], due to their hydrophilic nature, were successfully applied for enzymatic biosensors.

The use of photocured polymeric systems permits the use of standard photolithographic processes to form ion-sensitive membranes on all the devices on a wafer level. This may be beneficial for mass production of ion sensors. However, membranes cover only a small portion of the wafer area and most of the deposited pre-polymer composition will be washed away during the development stage, which may be regarded as a certain disadvantage taking into consideration the high cost of ionophores. A more economical solution to this problem is the use of microdispensers with which one can apply a certain volume of a pre-polymer mixture to the well formed by encapsulating layer over the ISFET gate region. This technique may be used to deposit membranes directly on a wafer or on individual encapsulated sensors, as presented in Figure 3. In this case it is easy to form thick membranes 
of 200-300 $\mu \mathrm{m}$ which may have a longer lifetime. By above method ion-sensitive membranes of different types may were formed on an integrated multi-sensor chip [58].

One of the problems that may arise in the case of photocurable polymer membranes is a photobleaching of the membrane components upon extended UV exposure during the polymerisation and encapsulation processes. It is known that the stability of tetraphenylborate ion is limited, especially in the presence of acids and oxidizing agents and under UV illumination [59]. Decomposition of tetraphenylborate derivatives takes place with the consumption of a proton, giving as a result neutral products. This means that the concentration of tetrakis(p-chlorophenyl)borate ion that is normally used for an ion selective membrane in order to reduce the resistance of the membrane and to obtain the better selectivity may depend on the time of UV exposure. The extent of interference of highly lipophilic anions ( $\mathrm{CNS}^{-}$for example) in solution may be used as an indicator for the K-TpClPB content in the membrane, as shown in Figure 4, where the calibration curves of sensors with membranes containing plasticizer and K-TpCIPB and polymerised with different exposure times are presented. For comparison the calibration curve for membrane without lipophilic anion is given too [60]. From Figure 4 it is clear that with increase of the exposure time the cationic response of the membrane switches to anionic at much lower concentrations of KCNS and selectivity of the sensor decreases.

Another problem that photocurable polymer membrane matrices may suffer is the impossibility to use some plasticizers or ionophores, especially in the case of radical initiation of polymerisation because they can inhibit this type of reaction. No polymerisation occurred when 2-nitrophenyl octyl ether (NPOE) or 4-nitrophenyl phenyl ether (NPPE), two of the most common plasticizers for bivalent ions like $\mathrm{Ca}$ or $\mathrm{Mg}$, are used in membrane compositions [13,19]. The presence of porphyrin, which acts as an ionophore in many anion selective membrane compositions, in case of urethane diacrylate also completely inhibits the photopolymerisation process [22]. This problem may be partly resolved by changing the type of initiation of photopolymerisation from radical to cationic [12,34] that is less susceptible to the inhibition by these substances. As a photoinitiator of cationic polymerisation process a mixture of quinone derivatives and phenyliodonium salt is used. It must be taken into consideration that introduction of photoinitiators may affect analytical parameters of sensors. It is well known that a photoinitiator is not totally consumed in the reaction [61] and though its concentration in the membranes is not very high, it is comparable with the concentration of an ionophore and lipophilic additives $(1-2 \% \mathrm{w} / \mathrm{w})$. This may result in that the products of fragmentation and unreacted substances alter the ion-selective properties of the resulting membranes. Usually the selectivity of membranes that were cured via cationic way is not very high $[12,17,34]$.

Attempts to prevent the leaching of ion active components from thin $(30-100 \mu \mathrm{m})$ membranes began with the synthesis of a so called copolymerisable plasticizer [62]. More lately "plasticizer-free" [36,37] or "self-plasticizing" [38,39] ion-selective membranes have been introduced. This work was performed by the group from University of Cambridge (UK) $[43,44,63,64]$ who studied different copolymers based on acrylate and methacrylate systems. Another plasticizer-free polymer membrane composition based on methyl methacrylate and decyl methacrylate (MMA-DMA) copolymer was proposed by the Bekker group $[65,66]$. The last two works describe a thermally initiated free radical polymerisation method but the opportunity of photocuring of such systems may be mentioned. The use of commercial acrylates (Epocryl DRH 370, ACE and Cardura from Shell, Amsterdam) by the group at the University of Twente was not successful and the resulting K-selective ISFETs demonstrated low sensitivity [67]. More 
interesting results were obtained by incorporation of methacrylate moieties in the polysiloxane by Reinhoudt et al. [37]. However, the synthesis of these siloxane polymers seems to require much effort. To avoid this complicated synthesis the use of a commercial oligosiloxane and a polar methacrylate was suggested [46]. In this case $\mathrm{K}$ - and Ca-sensitive ISFETs with stable electro-analytical parameters were reported.

Figure 4. Calibration curves for polyurethane membranes containing K-TpClPB and a plasticizer in solutions of highly lipophilic anion (KCNS). The membranes differ in the UV exposure time used for polymerisation: 1-2 minutes of irradiation; 2-10 minutes; 3-20 minutes; 4-membrane without K-TpCIPB and with 2 minutes of irradiation.

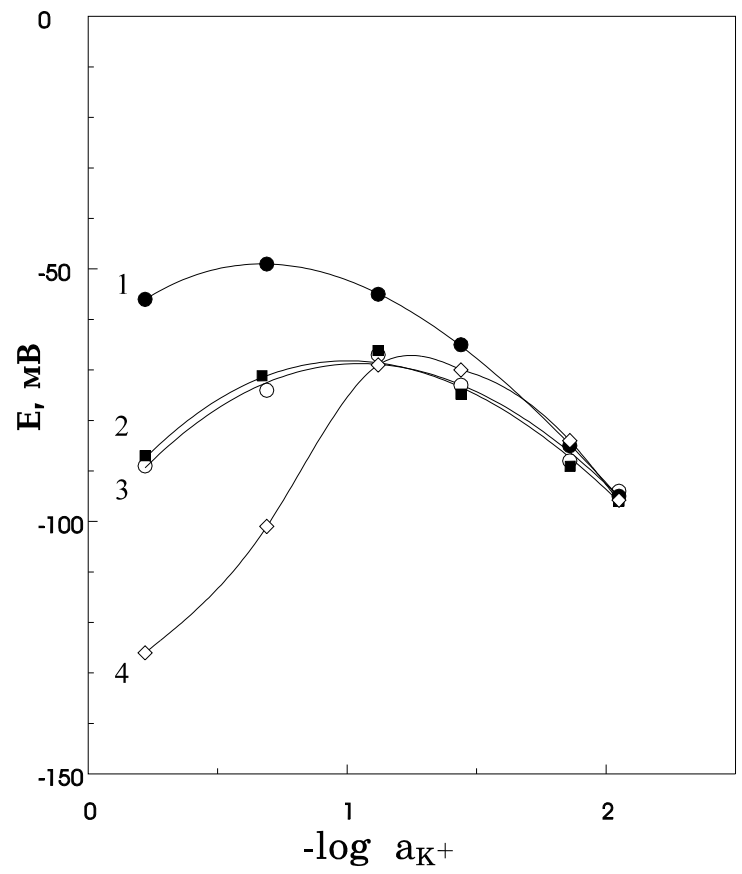

It must be noted that the absence of a free plasticizer within the membrane matrix may cause two problems. Firstly, the solubility of an ionophore and lipophilic additives in the membrane mixture will be decreased, which may seriously affect the sensor parameters like sensitivity, selectivity and limit of detection. Secondly, this will affect the mobility of charged species within the membrane phase which will result in a very high membrane impedance (50-200 M $\Omega$ ). In this case it is impossible to use a traditional ISFET-meter circuitry where changes of polarisation potential are registered under constant drain current conditions. The problem arises from the fact that membrane resistance in series with the capacitor of an ISFET gate have a large time constant which causes a delay in the drain current response when the gate potential is changed. In traditional ISFET-meter circuitry the drain current is maintained at a constant value by means of an operation amplifier, which directly controls the applied gate bias potential with negative feedback loop. However, at high values of membrane resistance, more than $10 \mathrm{M} \Omega$, and with a delay in drain current response the circuit starts to oscillate [22]. Introduction of lipophilic additives, like $\mathrm{K}-\mathrm{TpClPhB}$ and tetradodecylammonium tetrakis(4-chlorophenyl)borate (ETH 500) does not always help to reduce significantly the resistance [23].

Finally, another problem must be addressed. Due to the fact that in many cases commercial oligomers and not individual substances of known purity grade are used to prepare polymer membrane compositions 
it is difficult to expect good repeatability of the results when different batches of oligomers are used. These normally contain some additives of organic and inorganic nature originating from the industrial production or laboratory synthesis processes. Usually it is impossible to predict how these impurities will affect the analytical properties of ion selective membranes and to guarantee that their behaviour will be repeatable. This fact may explain why sometimes controversial results are published. Especially it concerns the selectivity of ion-selective membranes, a parameter that is very sensitive to the presence of ionic sites. In case of photocurable polymers this influence may be more pronounced because in addition to the impurities of polymers and cross-linkers the products of photobleaching may affect the sensor behaviour.

\section{Conclusions and Perspectives}

As a general conclusion, it is possible to note that nowadays scientific interest in ISFET sensors appears to be in decline. This is true not only for ChemFETs with photocurable membranes, but for all types of ISFETs. This can be explained by the fact that these devices are already quite well studied, suitable for various applications and with the fabrication technology established, they face more marketing problems than scientific ones. On the other hand, many groups which have been involved in the research on ISFETs throughout the years have changed research topics because financial support is probably more easily attracted for other, newer areas of research [68]. In any case, it is expected that in the future the on-line monitoring of industrial processes will become an important market for ISFET applications. In recent decades, the interest in quality control of food, water, products for human use and anything that could have adverse effects on the environment or human health has increased considerably. To date one of the best approaches to the quality control is provided by use of chemical sensor arrays with posterior multivariate analysis of their response. One of the systems that exists on the market now consists of an array of seven cross-selective sensors based on ISFETs for measuring organic as well as inorganic compounds, an autosampler, a software package and an electronic unit. This system under the name of $\alpha$ ASTREE is produced by the French company Alpha M.O.S. [69] and has been evaluated in food applications such as characterisation of flavours, quantitative analysis and quality control. According to the company's publicity the sensors can be fabricated with different membranes specially focused to the particular application demands of end-users.

One of the most important drawbacks of these arrays (or the so called "electronic tongues" in case of the analysis of liquids) reported until now is that normally they are composed by the same type of the sensors, either potentiometric, voltammetric or interdigitated electrodes [70]. This implies that a limited amount of data that can obtained with this analysis method. The application of microelectronic technologies permits monolithic integration of different electrochemical sensors using silicon technology. In this case it is possible to develop silicon chips with multi-sensor arrays that may include ion selective field effect transistors with various type of membranes and interdigitated electrodes used to measure the conductivity, redox potential or impedance parameters, amperometric sensors and other type of the sensors like temperature diode, for example [71]. As it was shown, this type of the sensors array can be successfully applied for mineral water analysis [72-73], as well as for grape juice and wine analysis [74]. It permits not only to distinguish the wines according to the grape variety and the vintage year, but also can be used for quantitative prediction of several sample parameters [74]. 
Another type of semiconductor based chemical sensors where application of photocurable membranes may be promising is light-addressable potentiometric sensors (LAPS), where the same field effect principle as in case of ISFET is used [47]. The advantage of the LAPS technique is that an arbitrary position on the sensing surface of the LAPS can be independently accessed with a light probe, e.g., scanning laser beam. This "light-addressability" facilitates its application to integrated multi-LAPS, in which different parts of the sensing surface are modified with different type of membranes (ion-selective, enzymatic, etc) [75]. These different microelectronic sensors combined together with microactuators (valve, pumps, channels, etc) and micro flow cells form analytical systems of next generation like $\mu$ TAS (micro total analysis system) or lab-on-a-chip devices.

\section{Acknowledgements}

Authors acknowledge the support of the Ramon \& Cajal program of the Ministry of Education of Spain and Spanish Ministry of Science and Innovation (MICINN), contract numbers AGL2005-07700C06 and AGL2008-05578-C05-05.

\section{References and Notes}

1. Jimenez, C.; Bratov, A.; Abramova, N.; Baldi, A. ISFET Based Sensors: Fundamentals and Applications. In Encyclopedia of Sensors; Grimes, C.A., Dickey, E.C., Pishko, M.V., Eds.; American Scientific Publishers: Stevenson Ranch, CA, USA, 2006; Volume 5, pp. 151-196.

2. Moody, G.J.; Slater, M.J.M.; Thomas, J.D.R. Membrane design and photocuring encapsulation of flatpack based ion-sensitive field effect transistors. Analyst 1988, 113, 103-108.

3. Rotje-Kamloth, K.; Janata, P.; Janata, J.; Josowicz, M. Electrochemical encapsulation for sensors. Sens. Actuat. 1989, 18, 415-425.

4. van den Vlekkert, H.H.; de Rooij, N.F.; van den Berg, A.; Grisel, A. Multi-ion sensing system on glass encapsulated pH-ISFETs and a pseudo-ReFET. Sens. Actuat. B 1990, 1, 395-400.

5. Smith, R.L.; Collins, S.D. Micromachined packaging for chemical microsensors. IEEE Trans. Electron. Devices 1988, 35, 787-792.

6. Sibbald, A.; Shaw, J.E.A. A Flow-through ion-selective field-effect transistor. Sens. Actuat. B 1987, 12, 297-300.

7. Dumschat, C.; Muller, H.; Rautschek, H.; Timpe, H.J.; Hoffmann, W.; Pham, M.T.; Huller, J. Encapsulation of chemically sensitive field-effect transistors with photocurable epoxy-resins. Sens. Actuat. B 1990, 2, 271-276.

8. Rickerl, P.G.; Stephanie, J.G.; Slota, P. Processing of photosensitive polyimides for packaging applications. IEEE Trans. Comp. Hybr. Manu. Tec. 1987, 10, 690-694.

9. Bratov, A.; Muñoz, J.; Dominguez, C.; Bartroli, J. Photocurable polymers applied as encapsulating materials for ISFET production. Sens. Actuat. B 1995, 25, 823-825.

10. Muñoz, J.; Bratov, A.; Mas, R.; Abramova, N.; Dominguez, C.; Bartroli, J. Planar compatible polymer technology for packaging of chemical microsensors. J. Electrochem. Soc. 1996, 143, 2020-2025.

11. Cattrall, R.W.; Iles, P.J.; Hamilton, I.C. Photocured polymers in ion-selective membranes. Anal. Chim. Acta 1985, 169, 403-406. 
12. Alexander, P.W.; Dimitrakopoulos, T.; Hibbert, D.B. A photo cured coated wire calcium ion selective electrode for use in flow injection potentiometry. Talanta 1997, 44, 1397-1405.

13. Cardwell, T.J.; Cattrall, R.W.; Iles, P.J.; Hamilton, I.C. Photocured polymers in ion-selective membranes. II: A calcium electrode for flow-injection analysis. Anal. Chim. Acta 1985, 177, 239-242.

14. Cardwell, T.J.; Cattrall, R.W.; Iles, P.J.; Hamilton, I.C. Photocured polymers in ion-selective membranes. 3. A potassium electrode for flow-injection analysis. Anal. Chim. Acta 1988, 204, 329-332.

15. Cardwell, T.J.; Cattrall, R.W.; Iles, P.J.; Hamilton, I.C. Photocured polymers in ion-selective membranes. 4. An UV-laser cured membrane for potassium. Anal. Chim. Acta 1989, 219, 135140.

16. Farrell, J.R.; Iles, P.J.; Dimitrakopoulos, T. Photocured polymers in ion-selectivee electrode membranes. Part 6: Photopolymerized lithium sensitive ion-selective electrodes for flow injection potentiometry. Anal. Chim. Acta 1996, 335, 111-116.

17. Alexander, P.W.; Dimitrakopoulos, T.; Hibbert, D.B. A six sensor array of coated-wire electrodes for use in a portable flow-injection analyzer. Electroanalysis 1998, 10, 707-712.

18. van der Wal, P.D.; Skowronska-Ptasinska, M.; van den Berg, A.; Sudholter, E.J.R.; Reinhoudt, D.N. New membrane materials for potassium-selective ion-sensitive field effect transistors. Anal. Chim. Acta 1990, 231, 41-52.

19. Bratov, A.; Abramova, N.; Muñoz, J.; Dominguez, C.; Alegret, S.; Bartroli, J. Photocurable polymer matrices for potassium-sensitive ion-selective electrode membranes. Anal. Chem. 1995, 67, 3589-3595.

20. Bratov, A.; Abramova, N.; Muñoz, J.; Dominguez, C.; Alegret, S.; Bartroli, J. Optimization of photocurable polyurethane membrane composition for ammonium ion sensor. J. Electrochem. Soc. 1997, 144, 617-621.

21. Bratov, A.; Abramova, N.; Dominguez, C.; Baldi, A. ISFET-based calcium ion sensoor with photocured polyurethane membrane sutable for ionised calcium determination in milk. Anal. Chim. Acta 2000, 408, 57-64.

22. Bratov, A.; Abramova, N.; Dominguez, C. Investigation of chloride sensitive ISFETs with different membrane compositions suitable for medical applications. Anal. Chim. Acta 2004, 514, 99-106.

23. Ipatov, A.; Abramova, N.; Bratov, A. Integrated multi-sensor chip with photocured polymer membranes containing copolymerised plasticizer for direct $\mathrm{pH}$, potassium, sodium and chloride ions determination in blood serum. Talanta 2009, DOI: TAL-D-08-02263R2 (in press).

24. Levichev, S.; Smirnova, A.L.; Khitrova, V.L.; Lvova, L.B.; Bratov, A.; Vlasov, Y.G. Photocurable carbonate-selective membranes for chemical sensors containing lipophilic additives. Sens. Actuat. B 1997, 44, 397-401.

25. Puig-Lleixa, C.; Jimenez, C.; Fabregas, E.; Bartroli, J. Potentiometric pH sensors based on urethane.acrylate photocurable polymer membranes. Sens. Actuat. B 1998, 49, 211-217.

26. Puig-Lleixa, C.; Ramíres-Garcia, S.; Jimenez, C.; Bartroli, J. Development of a new photopolymerizable membrane for monochloroacetate sensitive potentiomtric sensors. Anal. Chim. Acta 1999, 386, 13-19. 
27. Puig-Lleixa, C.; Jimenez, C.; Alonso, J.; Bartroli, J. Polyurethane-acrylate photocurable membrane for ion-selective field-effect transistors based urea biosensor. Anal. Chim. Acta 1999, 389, 179-188.

28. Puig-Lleixa, C.; Jimenez, C.; Bartroli, J. Acrylated polyurethane - photopolymeric membrane for amperometric glucose biosensor construction. Sens. Actuat. B 2001, 72, 56-62.

29. Sanchez, J.; del Valle, M. A new potentionmetric photocurable membrane selective to anionic surfactants. Electroanalysis 2001, 13, 471-476.

30. Jimenez, C.; Bartroli, J.; de Rooij, N.F.; Koudelka-Hep, M. Use of photopolymerizable membranes based on polyacrylamide hydrogels for enzymatic microsensor construction. Anal. Chim. Acta 1997, 351, 169-176.

31. Peper, S.; Tsagkatakis, I.; Bakker, E. Cross-linked dodecyl acrylate microspheres: novel matrices for plasticizer-free optical ion sensing. Anal. Chim. Acta 2001, 442, 25-33.

32. Ciobanu, M.; Wilburn, J.P.; Buss, N.I.; Ditavong, P.; Lowy, D.A. Miniaturized reference electrodes based on $\mathrm{Ag} / \mathrm{Ag}_{i} \mathrm{X}$ internal reference elements. I: Manufacturing and performance. Electroanalysis 2002, 14, 989-997.

33. Wydgladacz, K.; Durnas, M.; Parzuchowski, P.; Brzozka, Z.; Malinowska, E. Miniaturized sodium-selective sensors based on silicon back-side contact structure with novel self-plasticizing ion-selective membranes. Sens. Actuat. B 2003, 95, 366-372.

34. Dumschat, C.; Fromer, R.; Rautschek, H.; Muller, H.; Timpe, H.-J. Photolithographically pattenrnable nitrate-sensitive acrylate- based membrane. Anal. Chim. Acta 1991, 243, 179-182.

35. Knoll, M.; Cammann, K.; Dumschat, C.; Sundermeier, C.; Eshold, J. Potentiometric silicon microsnsor for nitrate and ammonium. Sens. Actuat. B 1994, 18-19, 51-55.

36. van den Berg, A.; Verney-Norberg, E.; Grisel, A. An ISFET-based calcium sensor using photopolymerized polysiloxane membrane. Sens. Actuat. B 1991, 4, 235-238.

37. Antonisse, M.; Lugtenberg, R.; Egberink, R.; Engbersen, J.; Reinhoudt, D.N. Durable nitrateselectivee chemically modified field effect transistirs based on polysoloxine membranes. Anal. Chim. Acta 1996, 332, 123-129.

38. Reinhoudt, D.N.; Engbersen, J.; Brzozka, Z.; van den Vlekkert, H.H.; Honig, G.; Holterman, H.; Verkerk, U. Development of durable $\mathrm{K}^{+}$-selective chemically modified field effect transistor with functionalized polysiloxane membranes. Anal. Chem. 1994, 66, 3618-3623.

39. van der Wal, P.D.; van den Berg, A.; de Rooij, N.F. Universal approach for the fabrication of $\mathrm{Ca}^{2+}, \mathrm{K}^{+}$and $\mathrm{NO}^{3-}$ sensitive membrane-ISFETs. Sens. Actuat. B 1994, 18-19, 200-207.

40. Levichev, S.; Bratov, A.; Vlasov, Yu.G. New photocurable composition for ISFET polymer membranes. Sens. Actuat. B 1994, 18-19, 625-628.

41. Kolytcheva, N.V.; Petrukhin, O.M.; Filipjeva, N.V.; Muller, H. Lohg-lived potentiometric sensors with poly(vinilchloride) and photopolymerized polyacrylate matrix anion sensitive membranes, applied on field effect transistors and silver coated ceramic substrate. Sens. Actuat. B 1998, 48, 491-500.

42. Kolytcheva, N.V.; Muller, H.; Marstalrz, J. Influence of the organic matrix on the properties of membrane coated ion sensor field-effect transistord. Sens. Actuat. B 1999, 58, 456-463.

43. Heng, L.Y.; Hall, E.A.H. Producing "self-plasticizing" ion-selective membranes. Anal. Chem. 2000, 72, 42-51. 
44. Heng, L.Y.; Hall, E.A.H. Assessing a photocured self-plasticised acrylic membrane recipe for $\mathrm{Na}^{+}$ and $\mathrm{K}^{+}$ion selective electrodes. Anal. Chim. Acta 2001, 443, 25-40.

45. Peper, S.; Ceresa, A.; Qin, Y.; Bakker, E. Plasticizer-free microspheres for ionophore-based sensing and extraction based on a methyl methacrylate-decyl methacrylate copolymer matrix. Anal. Chim. Acta 2003, 500, 127-136.

46. Edelmann, K.; Reiche, A.; Sander, B.; Mastalerz, J.; Muller, H. Copolymers from oligosiloxane methacrylte as a plasticizer-free membrane matrix for ion-selective sensors. Polymer 2005, 46, 407-417.

47. Ermolenko, Y.; Yoshinobu, T.; Mourzina, Yu.; Levichev, S.; Furuichi, K.; Vlasov, Y.G.; Schoning, M.J.; Iwasaki, H. Photocurable membranes for ion-selective light-addressable potentiometric sensor. Sens. Actuat. B 2002, 85, 79-85.

48. Marshall, A.J.; Blyth, J.; Davidson, C.A.B.; Lowe, C.R. PH-sensitive holographic sensors. Anal. Chem. 2003, 75, 4423-4431.

49. Mersal, G.A.M.; Khodari, M.; Bilitewski, U. Optimisation of the composition of a screen-printed acrylate polymer enzyme layer with respect to an improved selectivity and stability of enzyme electrodes. Biosen. Bioelectron. 2004, 20, 305-314.

50. Mourzina, I.G.; Yoshinobu, T.; Ermolenko, Y.E.; Vlasov, Y.G.; Schoning, M.J.; Iwasaki, H. Immobilization of urease and cholinesterase on the surface of semiconductor transducer for the development of light-addressable potentiometric sensors. Microchim. Acta 2004, 144, 41-50.

51. Tietje-Girault, J.; MacInnes, I.; Schroder, M.; Tennat, G.; Girault, H.H. Ptotopolymerisation of ion-selecttive membranes onto silicon nitride surfaces for ISFET fabrication. Electrochim. Acta 1990, 35, 777-783.

52. Miyahara, Y.; Moriizumi, T.; Ichimura, K. Integrated enzyme FETS for simultaneous detections of urea and glucose. Sens. Actuat. B 1985, 7, 1-10.

53. Sohn, B.; Cho, B.; Kim, C.; Kwon, D. ISFET glucose and sucrose sensors by using platinum electrode and photo-crosslinkable polymers. Sens. Actuat. B 1997, 41, 7-11.

54. Soldatkin, A.P.; Montoriol, J.; Sant, W.; Martelet, C.; Jaffrezic-Renault, N. A novel urea sensitive biosensor with extended dynamic range based on recombinant urease and ISFETs. Biosen. Bioelectron. 2003, 19, 131-135.

55. Jaffrezic-Renault, N.; Senillou, A.; Martelet, C.; Wan, K.; Chovelon, J.M. ISFET microsensors for the detection of pollutants in liquid media. Sens. Actuat. B 1999, 59, 154-164.

56. Wan, K.; Chovelon, J.M.; Jaffrezic-Renault, N.; Soldatkin, A.P. Sensitive detection of pesticide using ENFET with enzymes immobilized by cross-linking and entrapment method. Sens. Actuat. B 1999, 58, 399-408.

57. Bratov, A.; Abramova, N.; Muñoz, J.; Dominguez, C.; Alegret, S.; Bartroli, J. Ion sensor with photocurable polyurethane polymer membrane. J. Electrochem. Soc. 1994, 141, L111-L112.

58. Ipatov, A.; Abramova, N.; Bratov, A.; Dominguez, C. Integrated multi-sensor chip with sequential injection technique as a base for "electronic tongue" devices. Sens. Actuat. B 2008, 131, 48-52.

59. Rosatzin, T.; Bakker, E.; Suzuki, K.; Simon, W. Lipophilic and immobilized anionic additives in solvent polymeric membranes of cation-selective chemical sensors. Anal. Chim. Acta 1993, 280, 197-208. 
60. Abramova, N. Ion Selective Field Effect Transistors with fotocurable membrane selective for K and $\mathrm{NH}_{4}$ ions, PhD dissertation, St.Petersburg University, Saint Petersburg, Russia, 1998.

61. Pappas, S.P. Radiation Curing: Science and Technology. Plenum Press: New York, NY, USA, 1992.

62. Harrison, D.J.; Teclemariam, A.; Cunningham, L.L. Photopolimerization of plastisizers in ionsensitive membranes of solid-state sensors. Anal. Chem. 1989, 61, 246-251.

63. Heng, L.Y.; Hall, E.A.H. Methacrylic-acrylic polymers in ion-selective membrane: achieving the rightr polymer recipe. Anal. Chim. Acta 2000, 403, 77-89.

64. Heng, L.Y.; Hall, E.A.H. Taking the plasticizer out of methacrylic-acrylic membranes for K-selective electrodes. Electroanalysis 2000, 12, 187-193.

65. Qin, Y.; Peper, S.; Bakker, E. Plasticizer-free polymer membrane ion-selective electrodes containig a methacrylic copolymer matrix. Electroanalysis 2002, 14, 1375-1381.

66. Qin, Y.; Peper, S.; Radu, A.; Ceresa, A.; Bakker, E. Plasticizer-free polymer containing a covalently immobilized $\mathrm{Ca}^{2+}$-sellective ionophpre for potentiometric and optical sensors. Anal. Chem. 2003, 75, 3038-3045.

67. van der Wal, P.D.; Skowronska-Ptasinska, M.; van den Berg, A.; Sudholter, E.J.R.; Reinhoudt, D.N. New membrane materials for potassium-selective ion-sensitive field effect transistors. Anal. Chim. Acta 1990, 231, 41-52.

68. Bergveld, P. Thirty years of ISFETOLOGY What happened in the past 30 years and what may happen in the next 30 years. Sens. Actuat. B 2003, 88, 1-20.

69. Alpha M.O.S. Available Online: http://www.alpha-mos.com/technology/instruments.html (accessed on August 31, 2009).

70. Ciosek, P.; Wróblewski, W. Sensors arrays for liquid sensing- electronic tongue systems. Analyst 2007, 132, 963-978.

71. Moreno, L.; Baldi, A.; Merlos, A.; Abramova, N.; Ipatov, A.; Jimenez-Jorquera, C.; Bratov, A. Integrated multisensor for FIA-based electronic tongue application. IEEE Sens. J. 2008, 8, 608-615.

72. Moreno, L.; Merlos, A.; Abramova, N.; Jimenez, C.; Bratov, A. Multi-sensor array used as an "electronic tongue" for mineral water analysis. Sens. Actuat. B 2006, 116, 130-134.

73. Ipatov, A.; Abramova, N.; Bratov, A. Autocalibration technique based on SIA and integrated multisensor chip. Talanta 2008, 77, 581-586.

74. Codinachs, L.M.I.; Kloock, J.P.; Schoning, M.J.; Baldi, A.; Ipatov, A.; Bratov, A.; JimenezJorquera, C. Electronic integrated multisensor tongue applied to grape juice and wine analysis. Analyst 2008, 133, 1440-1448.

75. Yoshinobu, T.; Iwasaki, H.; Ui, Y.; Furuichi, K.; Ermolenko, Y.; Mourzina, Y.; Wagner, T.; Nather, N.; Schoning, M.J. The light-addressable potentiometric sensor for multi-ion sensing and imaging. Methods 2005, 37, 94-102.

(C) 2009 by the authors; licensee Molecular Diversity Preservation International, Basel, Switzerland. This article is an open-access article distributed under the terms and conditions of the Creative Commons Attribution license (http://creativecommons.org/licenses/by/3.0/). 